\title{
Impacts of Solar Energy on Butterfly Communities in Mediterranean Agro-Ecosystems
}

\author{
Clémence Guiller , Laurence Affre, ${ }^{a}$ Magali Deschamps-Cottin, ${ }^{b}$ Benoît Geslin, ${ }^{a}$ \\ Nicolas Kaldonski, ${ }^{a}$ and Thierry Tatoni ${ }^{a}$
}

${ }^{a}$ Institut Méditerranéen de Biodiversité et d'Ecologie marine et continentale, Aix Marseille Université, CNRS, IRD, Avignon

Université, Faculté des Sciences et Techniques St-Jérôme, Marseille Cedex 20, France; clemence.guiller@imbe.fr (for correspondence)

baboratoire Population Environnement Développement, Aix Marseille Université, IRD, LPED UMR_D 151, Marseille 13331, France

The rapid expansion of Utility-Scale Solar Energy (USSE) is expected to meet economic and environmental challenges that society faces today and in the future. Yet there is a paucity of comprehensive research on biodiversity responses to USSE. Here we investigated the impact of USSE on species movements via the correlations between landscape connectivity modeling and the similarity of butterfly communities given their life-history traits. Our results suggest that mobile butterflies cope with USSE while interpatch movement of sedentary butterflies does not depend on landscape structure. We provide land-managers and energy-developers with an innovative tool to assess the ecological integration of USSE.

Keywords: landscape connectivity, species movements, circuit theory, least-cost modeling, life-history traits

\section{INTRODUCTION}

With the expansion of global energy consumption and concerns over climate change [1], there has been a strong development of low-carbon energy technologies spurred by international policy drivers [2], such as Utility-Scale Solar Energy (USSE) (i.e., $\geq 1$ MW capacity). Over the last decade, the cumulative photovoltaic capacity has grown at a rate of $\sim 49 \%$ per year worldwide [1].

Aside from the economic impacts of renewable energy sprawl, there is a paucity of empirical research on the environmental impacts of solar energy in peer-reviewed scientific journals [3-0̂5]. Information is mostly documented in "gray" literature [3] and publications detail a set of potential impacts of USSE that remains theoretical [6,7]. While several authors concluded in the minimal to positive environmental impacts of USSE [6,7], others such as [3,8] express concerns about their adverse impacts on biodiversity (e.g., habitat loss and fragmentation, alteration of habitat quality, species assemblage changes, microclimate disturbance, and species mortality) both from the installation and during operation phases. Hence, USSE may disrupt the movement of species across the landscape [3] due to reduced connectivity between populations.

In this context, further insights regarding the impact of USSE on biodiversity are needed as a basis for making appropriate siting decisions and mitigating potential environmental impacts. To address these challenges, focusing on landscape connectivity is of particular interest as connectivity may be a key to maintain biodiversity in fragmented landscapes [9]. Landscape connectivity is "the degree to which landscape facilitates or impedes movement of organisms among resource patches" [10]. For the purpose of assessing landscape connectivity, modeling the ecological cost of moving through the landscape (e.g., least-cost modeling, circuit theory) has been demonstrated to be more appropriate than Euclidean distances [11-ô13]. Those techniques require resistance maps where a value for the reluctance to move throughout a land-use type is allocated to each pixel of a considered map. Therefore, circuit theory [14] and in particular least-cost modeling [15] are popular resistance-based techniques to examine species' response to landscape heterogeneity [16].

At the landscape scale, when two strongly linked patches exhibit similar communities in terms of composition, the spatial structure of species communities is then considered as a suitable proxy for estimating landscape connectivity [17] which indirectly details species movement. Butterfly communities (Rhopalocera) are widely acknowledged in the literature to be sensitive to habitat fragmentation [18,19] making them suitable models to study connectivity. Interestingly, as reviewed by Ref. 20, species responses to habitat loss and fragmentation are mediated by their life-history traits; hence, specialists and sedentary butterfly species are predominantly affected by habitat fragmentation compared to generalists and mobile species [21,22]. Therefore, discerning sedentary versus mobile species within butterfly communities may provide valuable information regarding the contrasting influence of landscape structure on movement patterns.

To our knowledge, assessing landscape connectivity at the level of species communities (see Refs. 17 and [23]) has not yet been applied to addressing the environmental impacts of USSE. Our aim was to address the role of USSE on butterfly movements by investigating landscape connectivity at the community-level and given butterfly life-history 

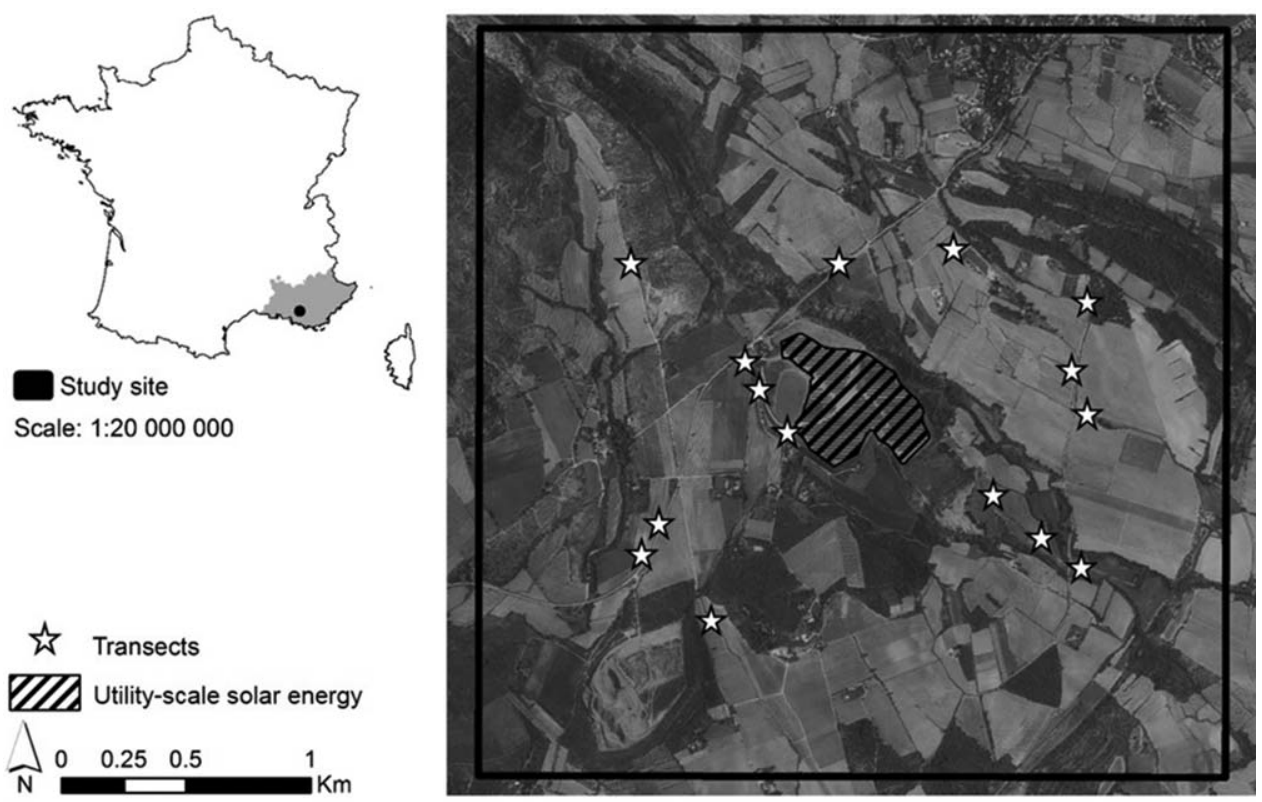

Figure 1. Localization of the study site (SE France) (left) and presentation of the sampling design with utility-scale solar energy (hatched in black) and the positioning of our 15 transects (white stars; right).

traits. While studies mainly focus on high-conservation-value areas such as the deserts of the southwestern United States (see Refs. 3,24, and 25) here, we consider USSE as one of the landscape features among others within a humandominated landscape and qualify its role relatively to other landscape features given a gradient of anthropogenic pressures as proceeded by Ref. 26. Ultimately, we provide energy-developers with a decision-support tool to mitigate the environmental impacts of USSE. Our basis hypotheses were that (i) two strongly linked habitats display similar butterfly communities, (ii) resistance-based algorithms would predict butterfly movement better than Euclidean distances, and (iii) there is a trait-mediated response to landscape structure, and in particular to USSE.

\section{MATERIALS AND METHODS}

\section{Study Site}

The study site is located in southeastern France (Puyloubier; $43^{\circ} 30^{\prime} \mathrm{N}, 5^{\circ} 39^{\prime} \mathrm{E}$; Figure 1) and represents a $3 \times 3 \mathrm{~km}$ window centered on a USSE. The facility was constructed in 2010 on a historically disturbed area, a former clay quarry and was thus not installed at the expense of a natural area. This ground mounted photovoltaic system extends over 18 ha with a capacity of $6.5 \mathrm{MW}$. The facility is embedded in a Mediterranean agro-ecosystem landscape dominated by vineyards $(47.4 \%$ of the study site; average size of the vineyards: $2.3 \pm 3.4 \mathrm{ha}$ ), and interspersed with seminatural grasslands arising from the abandonment of agricultural land (14.4\%; average size: $2.2 \pm$ $4.4 \mathrm{ha})$ and woody habitats colonized by Pinus halepensis (22.6\%). Built areas represent $12.6 \%$ of the study site.

\section{Parameterization of Resistance Values}

Modeling landscape connectivity with resistance-based algorithms involves a Geographic Information System (GIS) approach (ArcGIS Desktop 10.2 [27]). Resistance maps were derived from the study site map (digitalization of aerial photographs supplemented with ground data that we collected in July 2015). We defined nine land-use types to carefully depict landscape heterogeneity (i.e., buildings, grassy field margins, roads, road verges, seminatural grasslands, USSE, vineyards, water, and woody habitats). We obtained a $1 \mathrm{~m} \times$ $1 \mathrm{~m}$ raster map that was converted into resistance maps. Setting resistance values for each land-use type proceeded from the existing scientific knowledge of the ecology and movement patterns of semigrassland butterflies. Land-use types promoting mobility were attributed lower resistance values than those impeding it. Therefore, the resistance value of seminatural grasslands, i.e., butterflies' habitat, was set to 1 (the lowest resistance). Knowing that grassy linear elements (road verges and grassy field margins) may be suitable for butterflies and act as habitats and/or corridors [28-ô30], we assigned to these elements the lowest resistance value as well. Although most grassland butterflies typically avoid arable fields [31-ô33], here, we assumed that vineyards could facilitate displacements given a particular management strategy (i.e., delayed mowing) that enables the occurrence of complementary flowering resources between the rows of vineyards (see Ref. 29). Munguira and Thomas [28] emphasize that common butterfly species may cope with roads (here, resistance value set to 1 due to small and low traffic roads). Conversely, impervious areas (buildings, water) and in particular, woody habitats prevent the movements of grassland butterfly species [32,34,35] and as such, received higher resistance values (2-100 times more resistant than seminatural grasslands). Finally, we attributed distinct resistance values to USSE ranging from 1 to 100 . On this basis, we constructed eight resistance sets (Table 1 and Appendix A). We iteratively tested various combinations of resistance values to finely describe the relative contribution of each land-use type to butterfly movements (e.g., vineyards with varying resistance value $=1 / 5 / 100$ ) .

\section{Butterfly Sampling}

We recorded the presence and abundance of butterfly species in 15 transects scattered across the study site (Figure 1). More specifically, five were chosen within seminatural grasslands, five within field margins, and five within road verges, respectively. Those transects needed to meet three criteria: they were placed (i) in homogeneous areas encompassing attractive flowering resources, (ii) at least $500 \mathrm{~m}$ away from the boundaries of the $3 \times 3 \mathrm{~km}$ window of the 
Table 1. Resistance sets implemented into landscape connectivity algorithms. For example, for RS2, USSE is 15 times more resistant than open-habitats $($ value $=1$ ) and 6.7 times less resistant than woody habitats (value $=100)$.

\begin{tabular}{|c|c|c|c|c|c|c|c|c|}
\hline Land-use types & RS1 & RS2 & RS3 & RS4 & RS5 & RS6 & RS7 & RS8 \\
\hline Buildings & 100 & 100 & 100 & 100 & 100 & 100 & 100 & 100 \\
\hline Grassy field margins* & 1 & 1 & 1 & 1 & 1 & 1 & 1 & 1 \\
\hline Road verges* & 1 & 1 & 1 & 1 & 1 & 1 & 1 & 1 \\
\hline Roads & 1 & 1 & 1 & 1 & 1 & 1 & 1 & 1 \\
\hline Seminatural grasslands & 1 & 1 & 1 & 1 & 1 & 1 & 1 & 1 \\
\hline USSE & 100 & 15 & 40 & 100 & 100 & 1 & 1 & 1 \\
\hline Vineyards & 1 & 1 & 1 & 1 & 100 & 1 & 1 & 5 \\
\hline Water & 100 & 100 & 100 & 100 & 100 & 100 & 100 & 100 \\
\hline Woody habitats & 100 & 100 & 100 & 2 & 100 & 100 & 20 & 100 \\
\hline
\end{tabular}

*Grassy linear elements.

study site, and (iii) at least $10 \mathrm{~m}$ away from a patch boundaries within seminatural grasslands [22]. Transects were located in the immediate vicinity and further from the solar power installation (from 30 to $830 \mathrm{~m}$ ). None of them crossed the USSE area because we were denied access to the facility. Nevertheless, it would not significantly affect the quality of our analysis as we addressed interpatch movements rather than movements within patches. Operating short transect $(25 \mathrm{~m}$ long $\times 5 \mathrm{~m}$ wide) matched the width of grassy linear elements and ensured a sampling within homogeneous herbaceous cover as underlined by Ref. 36. Transects were visited four times between 6 July and 28 August 2015 under optimal weather conditions [37]. We walked along the transects at a uniform pace during 5 min to record all butterflies seen within the transect.

\section{Butterfly Community Similarity}

We used the Morisita-Horn index [38] to describe butterfly communities based on the similarity of species composition between pairwise transects. This index, which uses relative rather than the absolute abundance of species between two communities, ranges from 0 (denoting no overlap between sites) to 1 (denoting that species occur in the same proportions in both sites). We selected this index because Magurran and Wolda [38,39] evidenced its relative robustness to species richness and sample sizes. To investigate landscape connectivity while using a trait-based approach, we divided butterfly communities in two levels of mobility: "sedentary" (low dispersal abilities) and "mobile" (higher dispersal abilities) following Ref. 22. We referred to the mean dispersal distances of butterfly species predicted by Ref. 40. A species was defined as "sedentary" if its mean dispersal distance was less than $254 \mathrm{~m}$, i.e., the median of dispersal distances for all recorded species. Conversely, a species whose mean dispersal distance equaled or exceeded $254 \mathrm{~m}$ was "mobile." Species abundance was $\log (\mathrm{x}+1)$-transformed prior to calculations and pairwise similarity was then computed for both sedentary and mobile species using the "vegan" library in $\mathrm{R}$ 3.0.2. [41].

\section{Calibration of Landscape Connectivity Modeling via the Butterfly Community Similarity}

Least-cost modeling depicts the line that minimizes the cumulative cost of moving from a source to a destination patch [15] across a resistance map. Each pixel of the resistance map is assigned a value of the reluctance to move throughout a given land-use type. Least-cost modeling assumes that organisms have a complete knowledge of the landscape which enables them to follow the cheapest route. In the view of investigating conceptually distinct modeling approaches of landscape connectivity, circuit theory [14] is another common algorithm. Landscape is thus converted into an electrical circuit, i.e., a network of regularly spaced electrical nodes connected by resistors, whose values are defined by the resistance map. Resistors oppose the flow of electrical current (i.e., movement of organisms). Circuit theory would give convincing results because it complements the single least-cost path by multiple pathways presumably undertaken by moving organisms preferring low-resistance habitats [42]. For both least-cost modeling and circuit theory, the effective distance is then a measure of isolation or movement cost between pairs of patches; but according to circuit theory, it decreases as more pathways with low resistance connect pairwise patches [42]. We computed least-cost modeling and circuit theory on all $1 \mathrm{~m} \times 1 \mathrm{~m}$ resistance maps using algorithms implemented in the Cost distance and Circuitscape 4.0 toolboxes in ArcGIS Desktop 10.2, respectively. Points source and destination corresponded to the center of each transect. After application of both resistance-based algorithms, we obtained effective distances between pairwise transects. Then, we examined the correlations between the landscape connectivity models predicting intertransect effective or Euclidean distances and $\log (\mathrm{x}+1)$-transformed Morisita-Horn index, using generalized linear models (GLMs) (normal distribution, log-link function). We restricted the analysis to pairwise transects which were distant up to $1100 \mathrm{~m}$ in a straight line (i.e., approximating the highest mean dispersal distance for all recorded butterflies). To select the best predictive model of the similarity for sedentary and mobile communities, we used Akaike's information criterion corrected (AICc) for small sample size. Following the rule of $\Delta \mathrm{AICc} \leq 2$, models were less supportive of our empirical data if their relative difference of AICc to the best model exceeded 2. The selection procedure was strengthened by model probabilities $(\omega i)$ and evidence ratios calculated using "AICcmodavg" package in $\mathrm{R}$ [43]. We checked the significance of each GLM based on 10,000 permutations, as pairwise similarities and effective/Euclidean distances were statistically dependent. The statistical analyses were performed in R 3.0.2.

\section{RESULTS}

We recorded 267 mobile individuals and 491 sedentary individuals of 24 butterfly species (Appendix B). For mobile species, the Morisita-Horn index between pairwise transects was best predicted by effective distances calculated from RS8 implemented in circuit theory (model 16; Table 2). This resistance set indicated that the USSE was as easy to traverse as seminatural grasslands and grassy linear elements. The model explained $25.7 \%$ of the deviance. Butterfly community 
Table 2. Results of the GLMs analyses for mobile and sedentary species. RS: Resistance set; AICc: Akaike information criterion corrected; $\omega_{\mathrm{i}}$ : probability of the model $i$ (Akaike weight).

\begin{tabular}{|c|c|c|c|c|c|c|c|}
\hline & Model & RS & $\begin{array}{l}\text { Modeling } \\
\text { approach }\end{array}$ & AICc & $\triangle \mathrm{AICC}$ & $\omega_{i}$ & $\begin{array}{c}\text { Evidence } \\
\text { ratio }\end{array}$ \\
\hline \multirow[t]{18}{*}{ Mobiles species } & 1 & 1 & Least-cost & -19.37 & 12.1 & 0 & 423.1 \\
\hline & 2 & 1 & Circuit theory & -27.16 & 4.31 & 0.05 & 8.6 \\
\hline & 3 & 2 & Least-cost & -19.36 & 12.1 & 0 & 425.0 \\
\hline & 4 & 2 & Circuit theory & -27.82 & 3.64 & 0.08 & 6.2 \\
\hline & 5 & 3 & Least-cost & -19.36 & 12.1 & 0 & 425.0 \\
\hline & 6 & 3 & Circuit theory & -27.38 & 4.09 & 0.06 & 7.7 \\
\hline & 7 & 4 & Least-cost & -20.6 & 10.86 & 0 & 228.7 \\
\hline & 8 & 4 & Circuit theory & -22.56 & 8.91 & 0.01 & 86.2 \\
\hline & 9 & 5 & Least-cost & -20.55 & 10.92 & 0 & 234.6 \\
\hline & 10 & 5 & Circuit theory & -17.92 & 13.55 & 0 & 877.1 \\
\hline & 11 & 6 & Least-cost & -19.36 & 12.11 & 0 & 425.9 \\
\hline & 12 & 6 & Circuit theory & -29.42 & 2.05 & 0.17 & 2.8 \\
\hline & 13 & 7 & Least-cost & -21.54 & 9.93 & 0 & 143.4 \\
\hline & 14 & 7 & Circuit theory & -29.17 & 2.3 & 0.15 & 3.2 \\
\hline & 15 & 8 & Least-cost & -21.2 & 10.27 & 0 & 170.2 \\
\hline & 16 & 8 & Circuit theory & -31.47 & 0 & 0.47 & \\
\hline & 17 & & 11 model & -18.58 & 12.89 & 0 & 629.7 \\
\hline & 18 & & an distance & -20.47 & 10.99 & 0 & 244.0 \\
\hline \multirow[t]{18}{*}{ Sedentary species } & 19 & 1 & Least-cost & 8.67 & 1.72 & 0.04 & 2.37 \\
\hline & 20 & 1 & Circuit theory & 7.51 & 0.57 & 0.08 & 1.33 \\
\hline & 21 & 2 & Least-cost & 8.66 & 1.72 & 0.04 & 2.36 \\
\hline & 22 & 2 & Circuit theory & 7.71 & 0.77 & 0.07 & 1.47 \\
\hline & 23 & 3 & Least-cost & 8.66 & 1.72 & 0.04 & 2.36 \\
\hline & 24 & 3 & Circuit theory & 7.58 & 0.64 & 0.08 & 1.38 \\
\hline & 25 & 4 & Least-cost & 8.73 & 1.79 & 0.04 & 2.45 \\
\hline & 26 & 4 & Circuit theory & 6.94 & 0 & 0.11 & \\
\hline & 27 & 5 & Least-cost & 9.43 & 2.49 & 0.03 & 3.47 \\
\hline & 28 & 5 & Circuit theory & 8.21 & 1.27 & 0.06 & 1.88 \\
\hline & 29 & 6 & Least-cost & 8.63 & 1.68 & 0.05 & 2.32 \\
\hline & 30 & 6 & Circuit theory & 8.31 & 1.36 & 0.05 & 1.98 \\
\hline & 31 & 7 & Least-cost & 9.16 & 2.22 & 0.03 & 3.03 \\
\hline & 32 & 7 & Circuit theory & 7.81 & 0.86 & 0.07 & 1.54 \\
\hline & 33 & 8 & Least-cost & 8.56 & 1.61 & 0.05 & 2.24 \\
\hline & 34 & 8 & Circuit theory & 9.33 & 2.38 & 0.03 & 3.29 \\
\hline & 35 & & 11 model & 7.26 & 0.32 & 0.09 & 1.17 \\
\hline & 36 & & an distance & 9.13 & 2.19 & 0.04 & 2.98 \\
\hline
\end{tabular}

similarity decreased with increasing effective distances $(P$ value $<0.001)$. Although our model 16 was only $\sim 3$ times more plausible than the second (model 12; RS6) and third ranked-models (model 14; RS7), both alternative models also depict USSE as a facilitating land-use type and indicate varying effects for woody habitats (20 or 100 times more resistant than USSE) and vineyards being as permeable as both USSE and butterflies' habitats $(=1)$. Least-cost modeling and Euclidean distances were poor predictors of the MorisitaHorn index.

For sedentary species, model 26 (RS4 in circuit theory) detected that on average the similarity of butterfly communities had a tendency to decrease with increasing effective distances without being significant $(P$ value $=0.115)$. This model indicated that USSE is 100 times more resistant than open-habitats while woody habitats are 2 times more resistant than open-habitats. It explained $4.93 \%$ of the deviance. However, as stated, the first ranked-model was not significantly more discriminatory than alternative models of landscape connectivity (low model probabilities: $\omega_{i} \leq 0.11$ and models displayed $\Delta$ AICc $\leq 2.49$; Table 2). Evidence ratios were particularly weak (ranging from 1.17 to 3.47 ). In addition, the second model of landscape connectivity that best explained the spatial structure of butterfly communities was the null model.

\section{DISCUSSION}

We propose here a tool providing comprehensive information on how species perceive USSE. We demonstrated that mobile butterfly species cope with this man-made facility while landscape structure does not modulate the spatial structure of sedentary species communities.

\section{Contribution of Landscape Connectivity: Unraveling the Role of USSE for Butterfly Movements}

Our results indicate that for mobile species, two strongly linked transects tend to display similar butterfly communities (as expected in our basis hypothesis) while none of our models was statistically significant for sedentary species. Despite a simple parameterization of resistance sets, circuit theory outperformed other modeling approaches, i.e., leastcost and Euclidean distance (corroborating hypothesis 2). Multiple pathways between pairwise transects may improve the predictive power of our landscape connectivity models compared to the popular least-cost modeling (see Refs. 11 and [17] on other species groups), because it may bring more ecologically realistic information on how landscape structure shapes the movement of organisms than a single least-cost path model, in particular for species with high dispersal abilities. Knowing that the similarity of mobile butterfly communities is a reasonable proxy for landscape 
connectivity, we emphasize that interpatch movements are driven by landscape structure, consistent with Refs. 18 and [44]. We have also contributed to improving the understanding of the connectivity of grassland butterflies, and more specifically the impact of facilities such as USSE in humandominated landscapes.

The best resistance set (RS8) reports that USSE did not impede the movement of mobile butterfly species. Those species seemed to display a stronger propensity to move via seminatural grasslands, grassy linear elements, vineyards, and USSE rather than woody habitats and impervious surfaces within a human-dominated context. Grasslands and grassy linear elements indicate the lowest resistance because they provide both habitats [45] and complementary resources [29]. The role of grassy linear elements as corridor-structures for butterflies moving between distant grassland patches is widely acknowledged in the literature $[30,34,46]$. Here traversing one pixel of USSE is 100 times less costly than one of woody habitats which have previously been cited as dispersal barriers for open habitat butterflies [32,35]. The delayed mowing (up to August) both between rows of vineyards and of solar panels enables the occurrence of flowering resources even during the drought season, which may in turn limit the resistance values of both USSE and vineyards (see RS6, RS7). Lizée et al. [26] emphasized that vineyards located in peri-urban Mediterranean agro-ecosystems were not harmful for butterfly movements. Conversely, no evidence was found that landscape structure influences sedentary species (yet their abundance was twice as high as that of mobile species). This result is inconsistent with the literature that emphasizes the detrimental effects of habitat fragmentation on poorly mobile species $[21,22]$ but it may reflect the sufficient availability of resources within contemporary open habitats; therefore, sedentary butterflies remain in place. Conversely, we assume that a strong disturbance in these open habitats due to land-use changes would have affected the spatial structuration of sedentary butterfly communities. Furthermore, since sedentary butterflies move over limited distances, the similarity of communities could mainly result from local factors such as particular habitat or resources (e.g., significance of local conditions for sedentary species richness [47]) rather than isolation between habitat patches. Alternative explanations relate to (i) the spatial extent at which species respond to landscape structure that was too large to properly address ecological processes [45] or (ii) the parameterization of resistance sets that inaccurately reflects how sedentary species perceive the spatial arrangement of land-use types.

In accordance with the studies of Refs. 17 and [23] conducted on birds and plant communities, we highlight that community similarity is a reasonable proxy for landscape connectivity, and here, given species life-history traits. The trait-mediated response to landscape structure (hypothesis 3) has been widely reported in the literature (sedentary/mobile, generalist/specialist $[9,22,48]$ but we provide new evidences regarding the impact of USSE on butterfly communities to thus qualify its role on species movement. One of the interests of our study lies in the development of a cost-effective modeling approach validated by empirical data that improves our understanding of the ecological integration of USSE as an alternative to labor-extensive fieldwork methods (e.g., mark-release-recapture, recording flight paths [32,33]).

\section{Limitations and Perspectives}

Although our methodology underlines to a certain extent the influence of landscape structure on butterfly communities, we suggest to (i) increase the number of nearby transects (to statistically analyze processes at finer scales, which would be more appropriate for sedentary species) and (ii) improve the a priori assignment of resistance sets via quantitative estimates inferred from biologically meaningful data
[49], which would however involve labor-intensive fieldwork. (iii) The binary distinction of "sedentary" and "mobile" species based on median dispersal distance may be questionable for experts (e.g., Colias crocea being a migratory species should appear as "mobile" rather than "sedentary"). Nevertheless, we believe that here, the wide range of dispersal distances guarantees a relatively consistent distinction of butterfly species. (iv) Among the overriding factors that influence butterfly communities (diversity, abundance), it may be appropriate to encompass local factors such as patch size and habitat quality (nectar and/or larval host-plants resources, direct management practices [50-ô52]), especially for sedentary species. (v) Moreover, Refs. 22 and [52] emphasized that grassland butterfly communities could benefit from the complementary resources provided by forests and particularly forest edges (nectar, host plants, and shelter) which, coupled with the trait-mediated edge effect on organisms' behaviors [53], highlights the need to account for a varying edge resistance to improve landscape connectivity modeling. (vi) Finally, local and long-term experimental studies have to be conducted to determine the effects of fences and management strategies on biodiversity within USSE.

\section{CONCLUSIONS AND POLICY IMPLICATIONS}

Our study is part of an integrative approach confounding the planning, socioeconomic and environmental aspects of solar energy. Here, we fill the gap between biodiversity conservation and solar energy sprawl with an empirically validated modeling approach addressed to coworking energydevelopers and land-managers for a proactive thinking which will (i) provide on-site mitigation measures and (ii) guide siting decisions.

Given our findings and the ecology of grassland butterflies, we may emphasize a wide range of policy recommendations to enhance the environmental quality of USSE: (i) to revegetate areas between and under rows of solar panels once installed; (ii) to adapt the frequency of mowing to plant phenology; and (iii) to increase both the diversity of host plant species and the cover of flowering resources. Furthermore, siting-decisions could greatly benefit from the presented tool as it complements multicriteria GIS analysis conducted at regional scale to identify large potential areas for the implementation of solar energy [24,25,54,55] with consistent empirical data on how species mobility would be locally affected by USSE. To a certain extent, installing USSE on disturbed areas may limit the range and intensity of environmental impacts. Hence, the implementation of the studied USSE on a former clay quarry may explain why mobile butterflies perceive this facility as highly permeable. Inversely, we suggest that its installation on locally rich habitats would have been highly detrimental to butterfly communities, and particularly to sedentary species. To provide a clearer insight on this point, we must analyze the environmental impacts of a gradient of USSE installed in various habitats, and over time. In the upcoming years, industrials would be likely to work hand in hand with scientists to conduct BACI experiments (Before-After, Control-Impact) that would give qualitative and quantitative information to understand how biodiversity is affected by a new facility.

Here, we meet the need for a robust assessment of environmental impacts that is likely to be required in environmental compliance documents and ease the process of planning permission. We developed a pro-active method transferable to other renewable as well as conventional energy facilities, thus providing insights regarding their environmental impacts.

\section{ACKNOWLEDGMENTS}

This study was funded by the programme "Processus d'Intégration Ecologique de l'Energie Solaire" (PIESO) (Grant 
No. CT2201TTADEM0). We would like to thank field assistants for their help and Michael Paul for greatly improving the English of this paper (No. 4500241987). We are grateful for the assistance of Nicolas Maurel on butterfly species identification.

\section{LITERATURE CITATED}

1. International Energy Agency (2014). Technology roadmap solar photovoltaic energy (2014 Edition). Paris.

2. European Union (2009), Directive 2009/28/EC of the European Parliament and of the Council of 23 April 2009 on the promotion of the use of energy from renewable sources and amending and subsequently repealing Directives 2001/77/EC and 2003/30/EC, http://eur-lex.europa.eu/legal-content/ EN/TXT/PDF/?uri=CELEX:32009L0028\&from =en.

3. Lovich, J.E., \& Ennen, J.R. (2011). Wildlife conservation and solar energy development in the Desert Southwest, United States, BioScience, 61, 982-992.

4. Northrup, J.M., \& Wittemyer, G. (2013). Characterising the impacts of emerging energy development on wildlife, with an eye towards mitigation, Ecology Letters, 16, 112-125.

5. Horváth, G., Blahó, M., Egri, Á., Kriska, G., Seres, I., \& Robertson, B.. (2010). Reducing the maladaptive attractiveness of solar panels to polarotactic insects, Conservation Biology, 24, 1644-1653.

6. Tsoutsos, T., Frantzeskaki, N., \& Gekas, V. (2005). Environmental impacts from the solar energy technologies, Energy Policy, 33, 289-296.

7. Turney, D., \& Fthenakis, V. (2011). Environmental impacts from the installation and operation of large-scale solar power plants, Renewable \& Sustainable Energy Reviews, 15, 3261-3270.

8. Chiabrando, R., Fabrizio, E., \& Garnero, G. (2009). The territorial and landscape impacts of photovoltaic systems: Definition of impacts and assessment of the glare risk, Renewable \& Sustainable Energy Reviews, 13, 2441-2451.

9. Brückmann, S.V., Krauss, J., \& Steffan-Dewenter, I. (2010). Butterfly and plant specialists suffer from reduced connectivity in fragmented landscapes, Journal of Applied Ecology, 47, 799-809.

10. Taylor, P.D., Fahrig, L., Henein, K., \& Merriam, G. (1993). Connectivity is a vital element of landscape structure, Oikos, 68, 571-573.

11. McRae, B.H., \& Beier, P. (2007). Circuit theory predicts gene flow in plant and animal populations, Proceedings of the National Academy of Sciences, 104, 19885-19890.

12. Stevenson, C.D., Ferryman, M., Nevin, O.T., Ramsey, A.D., Bailey, S., \& Watts, K.. (2013). Using GPS telemetry to validate least-cost modeling of gray squirrel (Sciurus carolinensis) movement within a fragmented landscape, Ecology and Evolution, 3, 2350-2361.

13. Etherington, T.R., Perry, G.L.W., Cowan, P.E., \& Clout, M.N. (2014). Quantifying the direct transfer costs of common Brushtail possum dispersal using least-cost modelling: A combined cost-surface and accumulated-cost dispersal kernel approach, Plos One, 9, e88293.

14. McRae, B.H. (2006). Isolation by resistance, Evolution, 60, 1551-1561.

15. Adriaensen, F., Chardon, J.P., De Blust, G., Swinnen, E., Villalba, S., Gulinck, H., \& Matthysen, E.. (2003). The application of "least-cost" modelling as a functional landscape model, Landscape and Urban Planning, 64, 233247.

16. Cushman, S.A., McRae, B., Adriaensen, F., Beier, P., Shirley, M., \& Zeller, K.. (2013). Biological corridors and connectivity, In D. W. Macdonald \& K. J. Willis (Eds.), Key topics in conservation biology (Volume 2, pp. 384404), Oxford: Wiley.
17. Muratet, A., Lorrillière, R., Clergeau, P., \& Fontaine, C. (2012). Evaluation of landscape connectivity at community level using satellite-derived NDVI, Landscape Ecology, 28, 95-105.

18. Ricketts, T.H. (2001). The matrix matters: Effective isolation in fragmented landscapes, The American Naturalist, 158, 87-99.

19. Öckinger, E., Bergman, K.-O., Franzén, M., Kadlec, T., Krauss, J., Kuussaari, M., Pöyry, J., Smith, H.G., SteffanDewenter, I., \& Bommarco, R.. (2011). The landscape matrix modifies the effect of habitat fragmentation in grassland butterflies, Landscape Ecology, 27, 121-131.

20. Ewers, R.M., \& Didham, R.K. (2006). Confounding factors in the detection of species responses to habitat fragmentation, Biological reviews of the Cambridge Philosophical Society, 81, 117-142.

21. Ekroos, J., Heliölä, J., \& Kuussaari, M. (2010). Homogenization of lepidopteran communities in intensively cultivated agricultural landscapes, Journal of Applied Ecology, 47, 459-467.

22. Villemey, A., van Halder, I., Ouin, A., Barbaro, L., Chenot, J., Tessier, P., Calatayud, F., Martin, H., Roche, P., \& Archaux, F.. (2015). Mosaic of grasslands and woodlands is more effective than habitat connectivity to conserve butterflies in French farmland, Biological Conservation, 191, 206-215.

23. Gil-Tena, A., Nabucet, J., Mony, C., Abadie, J., Saura, S., Butet, A., Burel, F., \& Ernoult, A.. (2014). Woodland bird response to landscape connectivity in an agriculturedominated landscape: A functional community approach, Community Ecology, 15, 256-268.

24. Cameron, D.R., Cohen, B.S., \& Morrison, S.A. (2012). An approach to enhance the conservation-compatibility of solar energy development, PLoS One, 7, e38437.

25. Stoms, D.M., Dashiell, S.L., \& Davis, F.W. (2013). Siting solar energy development to minimize biological impacts, Renewable Energy, 57, 289-298.

26. Lizée, M.-H., Bonardo, R., Mauffrey, J.-F., BertaudièreMontes, V., Tatoni, T., \& Deschamps-Cottin, M.. (2011). Relative importance of habitat and landscape scales on butterfly communities of urbanizing areas, Comptes Rendus Biologies, 334, 74-84.

27. ESRI (2013). ArcGIS Desktop: Release 10. Redlands, CA: Environmental Systems Research Institute.

28. Munguira, M.L., \& Thomas, J.A. (1992). Use of road verges by butterfly and burnet populations, and the effect of roads on adult dispersal and mortality, Journal of Applied Ecology, 29, 316-329.

29. Ouin, A., Aviron, S., Dover, J., \& Burel, F. (2004). Complementation/supplementation of resources for butterflies in agricultural landscapes, Agriculture, Ecosystems \& Environment, 103, 473-479.

30. Delattre, T., Vernon, P., \& Burel, F. (2013). An agrienvironmental scheme enhances butterfly dispersal in European agricultural landscapes, Agriculture, Ecosystems \& Environment, 166, 102-109.

31. Dover, J.W. (1990). Butterflies and wildlife corridors, The Game Conservancy Review, 1989, 62-64.

32. Ouin, A., Martin, M., \& Burel, F. (2008). Agricultural landscape connectivity for the meadow brown butterfly (Maniola jurtina), Agriculture, Ecosystems \& Environment, 124, 193-199.

33. Loos, J., Kuussaari, M., Ekroos, J., Hanspach, J., Fust, P., Jackson, L., \& Fischer, J.. (2014). Changes in butterfly movements along a gradient of land use in farmlands of Transylvania (Romania), Landscape Ecology, 30, 625-635.

34. Delattre, T., Pichancourt, J.-B., Burel, F., \& Kindlmann, P. (2010). Grassy field margins as potential corridors for butterflies in agricultural landscapes: A simulation study, Ecological Modelling, 221, 370-377. 
35. Kallioniemi, E., Zannese, A., Tinker, J.E., \& Franco, A.M.A. (2014). Inter- and intra-specific differences in butterfly behaviour at boundaries, Insect Conservation and Diversity, 7, 232-240.

36. Lizée, M.-H., Mauffrey, J.-F., Tatoni, T., \& DeschampsCottin, M. (2011). Monitoring urban environments on the basis of biological traits, Ecological Indicators, 11, 353-361.

37. Pollard, E. (1977). A method for assessing changes in the abundance of butterflies, Biological Conservation, 12, $115-134$.

38. Magurran, A.E. (1988). Ecological diversity and its measurements, Princeton, NJ: Princeton University Press.

39. Wolda, H. (1981). Similarity indices, sample size and diversity, Oecologia, 50, 296-302.

40. Stevens, V.M., Trochet, A., Blanchet, S., Moulherat, S., Clobert, J., \& Baguette, M.. (2013). Dispersal syndromes and the use of life-histories to predict dispersal, Evolutionary Applications, 6, 630-642.

41. R Development Core Team (2013). R: A language and environment for statistical computing, Vienna, Austria: R Foundation for Statistical Computing.

42. McRae, B.H., Dickson, B.G., Keitt, T.H., \& Shah, V.B. (2008). Using circuit theory to model connectivity in ecology, evolution, and conservation, Ecology, 89, 2712-2724.

43. Burnham, K.P., Anderson, D.R., \& Huyvaert, K.P. (2010). AIC model selection and multimodel inference in behavioral ecology: some background, observations, and comparisons, Behavioral Ecology and Sociobiology, 65, 23-35.

44. Sutcliffe, O.L., Bakkestuen, V., Fry, G., \& Stabbetorp, O.E. (2003). Modelling the benefits of farmland restoration: Methodology and application to butterfly movement, Landscape and Urban Planning, 63, 15-31.

45. Flick, T., Feagan, S., \& Fahrig, L. (2012). Effects of landscape structure on butterfly species richness and abundance in agricultural landscapes in eastern Ontario, Canada, Agriculture, Ecosystems and Environment, 156, 123-133.
46. Ries, L., Debinski, D.M., \& Wieland, M.L. (2001). Conservation value of roadside prairie restoration to butterfly communities, Conservation Biology, 15, 401-411.

47. Öckinger, E., Franzén, M., Rundlöf, M., \& Smith, H.G. (2009). Mobility-dependent effects on species richness in fragmented landscapes, Basic and Applied Ecology, 10, $573-578$

48. Öckinger, E., Schweiger, O., Crist, T.O., Debinski, D.M., Krauss, J., Kuussaari, M., Petersen, J.D., Pöyry, J., Settele, J., Summerville, K.S., \& Bommarco, R.. (2010). Life-history traits predict species responses to habitat area and isolation: A cross-continental synthesis, Ecology Letters, 13, 969-979.

49. Zeller, K.A., McGarigal, K., \& Whiteley, A.R. (2012). Estimating landscape resistance to movement: A review, Landscape Ecology, 27, 777-797.

50. Thomas, J.A., Bourn, N.A., Clarke, R.T., Stewart, K.E., Simcox, D.J., Pearman, G.S., Curtis, R., \& Goodger, B.. (2001). The quality and isolation of habitat patches both determine where butterflies persist in fragmented landscapes, Proceedings of the Royal Society B: Biological Sciences, 268, 1791-1796.

51. Dover, J., \& Settele, J. (2008). The influences of landscape structure on butterfly distribution and movement: A review, Journal of Insect Conservation, 13, 3-27.

52. Krämer, B., Poniatowski, D., \& Fartmann, T. (2012). Effects of landscape and habitat quality on butterfly communities in pre-alpine calcareous grasslands, Biological Conservation, 152, 253-261.

53. Ries, L., \& Debinski, D.M. (2001). Butterfly responses to habitat edges in the highly fragmented prairies of Central Iowa, Journal of Animal Ecology, 70, 840-852.

54. Fluri, T.P. (2009). The potential of concentrating solar power in South Africa, Energy Policy, 37, 5075-5080.

55. Watson, J.J.W., \& Hudson, M.D. (2015). Regional scale wind farm and solar farm suitability assessment using GIS-assisted multi-criteria evaluation, Landscape and Urban Planning, 138, 20-31. 